\title{
Carnets
}

Revue électronique d'études françaises de l'APEF

Première Série - 4 | 2012

(Res)sources de l'extravagance

\section{L'extravagance du berger extravagant de Charles Sorel (1627-1634) : un concept heuristique de la création fictionnelle au XVIIe siècle}

\section{Anne-Elisabeth Spica}

\section{OpenEdition}

Journals

Édition électronique

URL : http://journals.openedition.org/carnets/6586

DOI : $10.4000 /$ carnets.6586

ISSN : 1646-7698

Éditeur

APEF

Édition imprimée

Date de publication : 1 janvier 2012

Pagination : 31-46

Référence électronique

Anne-Elisabeth Spica, «L'extravagance du berger extravagant de Charles Sorel (1627-1634) : un concept heuristique de la création fictionnelle au XVIIe siècle ", Carnets [En ligne], Première Série 4 | 2012, mis en ligne le 20 juin 2018, consulté le 30 avril 2019. URL : http://journals.openedition.org/ carnets/6586; DOI : 10.4000/carnets.6586

\section{(C) $(1) \Theta$}

Carnets est mis à disposition selon les termes de la licence Creative Commons - Atribution - Pas d'utilisation commerciale 4.0 International. 


\title{
L'EXTRAVAGANCE DU BERGER EXTRAVAGANT DE CHARLES SOREL (1627-1634) un concept heuristique de la création fictionnelle au XVII siècle
}

\author{
ANNE-ELISABETH SPICA \\ Université Paul Verlaine - Metz \\ spica@univ-metz.fr
}

\begin{abstract}
Résumé
Le Berger extravagant, publié par Charles Sorel en 1627, met en scène les aventures d'un jeune homme qui a décidé de conformer sa vie à celle des bergers de pastorales. Ainsi le roman met systématiquement en miroir les procédés du genre; il est d'ailleurs réintitulé L'Anti-roman lors de la seconde édition en 1633. De ce fait, la figure de l'extravagant impose un point de vue constamment décentré pour mieux discerner les orientations de ce que doit être un récit fictionnel. Comment raconter les aventures d'un extravagant permet-il de refonder pragmatiquement le genre romanesque autour des années 1630 en France?
\end{abstract}

\begin{abstract}
Le Berger extravagant's plot, a novel published by Charles Sorel in 1627, is based on the adventures of a young man who has decided to live his life as the shepherds in pastoral narratives. The novel, entitled Anti-Novel in the second edition of 1633, mirrors the processes of its genre. Thus, the character of the extravagant hero suggests a permanent off-centre point of view which creates a better perspective in considering what should be fiction. How does telling the adventures of an extravagant allow the pragmatic refoundation of the novel around the year 1630 in France?
\end{abstract}

Mots-clés: Charles Sorel, théorie du roman, théorie de la lecture, vraisemblable, allégorie Keywords: Charles Sorel, theory of narrative, theory of interpretation, verisimilitude, allegory 
Le Berger extravagant ${ }^{1}$ fut sans doute l'une des tentatives les plus ambitieuses du roman français au XVII ${ }^{e}$ siècle. Charles Sorel, qui s'était déjà fait apprécier d'un large public pour son Francion (1623), décida en 1627 de s'attaquer aux fictions narratives idéalisantes en écrivant un roman dont la dynamique narrative reposerait sur la mise en œuvre parodique des topoï pastoraux et héroïques de manière à en démontrer l'inanité tout en proposant un nouveau modèle romanesque: celui du roman comique $^{2}$ dont la mimesis est moins destinée à susciter l'ébahissement devant des héros inaccessibles que la délectation morale devant la représentation distanciée du monde tel qu'il va, pour emprunter la terminologie d'Amyot au "Proesme" de sa traduction des Éthiopiques. Ce roman critique du romanesque ou AntiRoman, comme Sorel l'intitula dans la seconde édition de 1633-1634, met ainsi en scène un jeune homme, Lysis, qui, à trop lire les romans pastoraux, comme Don Quichotte avant lui les romans de chevalerie ${ }^{3}$, s'est pris pour un berger de L'Astrée et a décidé de rejouer pour mieux les accomplir toutes les aventures des héros amoureux; ses tentatives tournent systématiquement à la catastrophe jusqu'au moment où il est guéri de sa folie par ses compagnons, (une bande de jeunes nobles désireux de se jouer de lui dans la campagne briarde, tout en prétendant l'avoir conduit dans le Forez urféen pour l'aider à réaliser son rêve.

Entre folie avérée de la mélancolie érotique ${ }^{4}$ et mépris des repères qui constituent I'horizon de référentialité pour le lecteur, l'extravagant est installé systématiquement à la marge, sur les seuils du récit et de la vie, selon l'étymologie même de l'adjectif de nature qui le définit. Or, dans un texte destiné à mettre en miroir, à travers 14 livres de récit commentés par 14 livres de Remarques, les procédés de l'écriture romanesque, cette figure ne cesse de porter à faux pour mieux faire saillir par contraste les orientations de ce que doit être un récit de fiction, entre erreurs d'interprétation des récits-source, errances dans l'invention de

\footnotetext{
1 Le Berger extravagant. Où, parmy des fantaisies Amoureuse on void les impertinences des Romans et de la Poësie, Paris. T. Du Bray, 1627-1628, avec privilège du roi. 4 parties en 3 tomes in- $8^{\circ}$ de XXVI-961, VII-890 et XVI818 p.; L'Anti-Roman ou l'histoire du Berger Lysis, accompagnee de ses remarques, Paris, T. Du Bray, 16331634. 2 parties en 2 tomes in- $8^{\circ}$ de IV-13-III-1136 p. (I. I-VII) et IV-1134 p. (I. VIII-XIV). Toutes nos références dans notre édition de L'Anti-Roman, à paraître chez H. Champion. Le premier chiffre, romain, renvoie au numéro du livre, précédé de "R. " quand il s'agit des Remarques; le second, arabe, à la pagination de 1633-1634.

2 Sur ce genre apparu en France au XVII ${ }^{\mathrm{e}}$ siècle, dont Sorel fut l'un des grands promoteurs, voir Serroy, 1981.

3 Les liens sont étroits entre le roman de Sorel et celui de Cervantès. Sorel connaît bien l'œuvre de son illustre prédécesseur (voir Bardon, 1931; Zerari-Penin, 2007); il en réécrit nombre d'épisodes au sein du Berger extravagant et adhère au même projet de refondation romanesque, qu'il exacerbe dans le Berger extravagant en actualisant l'extravagance au goût littéraire du jour (romans hellénistiques et pastoraux) et en ajoutant aux livres de fiction les livres de Remarques, de manière à mettre radicalement au jour la métalittérarité inhérente au roman et indispensable à sa survie, contre un modèle irrecevable du fait même de l'idéalisation à laquelle il invite ses lecteurs mais par laquelle il les égare.

4 La mélancolie, en particulier la mélancolie érotique, fait l'objet de plusieurs traités médicaux à la fin du $X V I^{\mathrm{e}}$ siècle et au début du XVII en France. Pour la précision médicale des symptômes prêtés par Sorel à son héros, voir Alet, 2002. Cette pathologie, dont Sorel décrit le développement jusqu'à la cure, invite donc à discuter la limitation chez Blanckaert, 2004 de la folie extravagante à la sottise (considérée comme non pathologique, tout en prenant en compte sa valeur de révélateur fictionnel selon Bakhtine, 1978: 214-233).
} 
nouveaux et absurdes modèles narratifs par le héros, et refiguration en contrepoint de ces modèles. C'est ce principe de décentrement et de recentrement pragmatique que nous aimerions étudier: Sorel y instruit un modèle destiné à refonder le genre romanesque autour des années 1630 en France.

\section{Un décentrement essentiel}

Le personnage de l'extravagant-héros de roman est silhouetté de telle sorte qu'il inverse les procédés romanesques qui constituent l'horizon d'attente du lecteur familier des bergeries littéraires: un héroïsme amoureux absolu et désincarné, une sublimité singulière qui se transmet à ses proches, un univers régi par une topique intransposable, celle d'un monde isolé dont le charme et la crédibilité tiennent à l'artifice social et narratif assumés par l'auteur et son public (Lavocat, 1998). Lysis, croyant parfaire les attitudes de Céladon dans L'Astrée, mais sans renoncer aux exigences du corps, n'arrive au mieux qu'à une ridicule pantomime, de même que ses partis-pris langagiers, eux aussi inspirés des romans ou de la Fable, le rendent inaudible (Blanckaert, 2004: 376-379); sa poursuite amoureuse selon les codes pastoraux n'aboutit qu'à l'incompréhension méfiante de l'aimée ${ }^{5}$. II ne cesse de confondre les topoï du monde possible romanesque et les situations réelles du monde référentiel (qui peuvent au demeurant les inspirer): il juge une dispute entre paysans lors d'un mariage à l'aune des combats des Lapithes et des Centaures et promet de métamorphoser les factieux comme Apollon l'a fait des paysans de Lycie (IX, 182-183); il réajuste le vocabulaire agricole en fonction du pastoral (IX, 185); il prend plusieurs personnages pour des figures romanesques, qu'elles soient singulières ou topiques, ou bien pour des divinités mythologiques 6 ; mieux - ou pire dans la superposition aveugle de la fiction et du réel -, il souhaite que l'on ne joue plus de théâtre qu'en décors naturels (IX, 239-241).

En court-circuitant par l'absurde les motifs narratifs traditionnels, Lysis oblige ceux qui le côtoient, comme par contagion d'extravagance, à entrer dans sa logique dévoyée. En témoigne cette réplique du meneur de jeu au tuteur de Lysis, Adrian, qui l'accuse de faire sombrer son cousin dans la folie:

Vous m'avez osté ce pauvre garçon d'entre les mains, et me promettant que vous le traitteriez bien, vous l'avez amené icy parmy des gens qui luy ont fait perdre l'esprit

\footnotetext{
5 Les échecs répétés constituent un argument décisif pour convaincre Lysis à renoncer définitivement à son comportement: XIV, 1024.

6 La mère de Clarimond, l'ennemi des romans, est prise pour la sorcière Felicia dans la Diana de Montemayor (III, 460); des bourgeois de retour de beuverie qui l'arrêtent, pour des pirates venus l'enlever (II, 244); Anselme, le jeune noble qui décide de s'en amuser, pour le dieu Pan (I, 19), les jeunes femmes ou les servantes de la compagnie briarde pour des hamadryades ou des nymphes (V-IX)...
} 
tout à fait. C'est bien tout au contraire, respondit Anselme, car s'ils font les insensez, comme vous voyez quelquefois, vostre cousin en a esté la cause ${ }^{7}$. [...] il les a pervertis, et leur a communiqué toutes ses mauvaises opinions. Si je n'eusse bien pris garde à moy, et si je ne me fusse tousjours esloigné de luy, il m'alloit aussi faire prendre le grand chemin de la folie. J'ay de bons tesmoins qui vous prouveront qu'il m'a cent fois voulu persuader de me faire berger. (XII, 701-702).

L'entourage de Lysis adopte un comportement ${ }^{8}$ et tient des propos au diapason de cette logique pervertie, comme le souligne Sorel dans les Remarques:

Carmelin ayant confirmé la pluspart des choses que son maistre a dites, Adrian est si plaisant et si naï, qu'il dit qu'il faut donc qu'il ramene son cousin à Paris, pource que l'on ne trouve point là de dragons ny de bossus qui vous battent, ny de sorciers qui vous changent en arbre, et que la Justice les puniroit s'ils l'avoient fait. Voila une agreable persuasion pour le faire revenir. (R.XII, 742-743)

De fait, le héros n'a d'autre système de référence que l'univers livresque, qui modèle entièrement son comportement. Cette confusion à la source de son extravagance, comme celle de Don Quichotte, a pour conséquence de priver le personnage de toute inscription dans un univers de référence, qu'il s'agisse de l'univers référentiel du lecteur, bien sûr, mais aussi de l'univers fictionnel en général: Lysis n'appartient ni à celui des fictions idéalisées qu'il ne parvient qu'à singer, ni à l'univers comique organisé par le narrateur. Cet entre-deux fictionnel devenu son lieu propre par défaut est un espace littéraire inopérant. Imiter les topoï pris pour le réel au lieu de les discerner comme tels par rapport à ce même réel conduit à prendre les mots pour les choses et les paroles pour les actes.

Le berger ne se vit qu'à travers le verbe et les récits: en amont, ceux de la Fable et des romans auxquels il conforme jusqu'à sa mise, dont la narration souligne à loisir

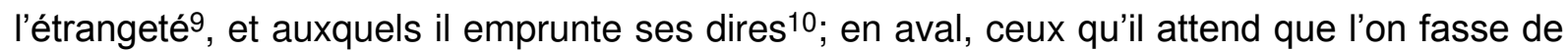
ses aventures et ceux qu'il propose lui-même de ses actes. Tous le conduisent à la marge du corps social et fictionnel agissant au sein duquel il est situé. Ainsi l'amoureux berger prend à la lettre le "commandement sans commandement" (VI, 923) de celle qu'il aime,

\footnotetext{
7 Ces personnages (Meliante, Polidor et Philiris) se sont montrés, pour leur première apparition dans la fiction, comme de véritables frères jumeaux en extravagance du Berger (VI, 905-914), avant que l'on découvre qu'ils feignent eux aussi la folie pastorale pour se jouer de Lysis.

8 Ainsi, quand le berger feint de s'être suicidé, le narrateur souligne à la fois ses mouvements sur son lit de mort et l'incapacité de ceux qui l'entourent à les percevoir, comme à sentir la chaleur de son corps quand ils le touchent (XII, 691).

9 I, 30-31, 33; III, 344, 445; IX, 218; X, 305-306, 363-365; XI, 563; XIV, 1033.

10 "[...] toutes les paroles de Lysis sont prises des Poëtes" (R.I, 136-137); "je n'ay fait cecy que pour monstrer que Lysis ne dit rien qu'il n'ait apris dans les livres d'amour" (R.XIV, 1064).
} 
Charite, une fois qu'elle lui a ordonné de ne plus lui obéir (VI, 872). L'intimation paraphrase le commandement initial d'Astrée à Céladon (ce qui la rend absolue à ses yeux), tout en proposant une action impossible (pour se conformer à la volonté de l'amante, il ne faut pas s'y conformer); en choisissant de rester fidèle à la lettre, le berger accepte sa propre négation: le suicide, mais dont il orchestrera seulement la mise en scène - une mort en mots - au I.XII. D'autre part, Lysis demande successivement aux deux meilleurs orateurs du roman, Clarimond et Philiris, d'écrire son "histoire", c'est-à-dire le roman de ses aventures. II est symptomatique de voir le romancier souligner de manière récurrente à quel point Lysis inscrit dans cette biographie romanesque l'achèvement de sa trajectoire, en fonction d'une mimesis, paradoxale en roman, où un personnage de papier trouverait la réalité de son existence non pas dans une référentiation commune avec le lecteur (le personnage est fictionnellement vivant parce qu'il ressemble, si idéalisé soit-il en berger ou en chevalier néocourtois, à un être de chair et de sang), mais dans la sublimation fictionnelle qui confère l'unique vie digne de ce nom (le personnage est réellement vivant parce qu'il a dépouillé sa contingence humaine pour n'être plus forgé qu'avec les mots de la création littéraire): être, c'est être dit (ou peint ${ }^{11}$ ) romanesquement ${ }^{12}$. Enfin, les récits que Lysis invente de ses propres aventures le placent à l'écart du système de référence dans lequel il est inscrit, le quotidien du roman comique. Ils l'installent dans un monde fabuleux lorsqu'il raconte à Carmelin son valet les nuits en compagnie des divinités des rivières et des bois au I.V, celui de sa métamorphose en saule; dans un Autre monde médiéval et onirique, voire un ailleurs extraterrestre à l'occasion de l'Aventure magique de Lysis, transporté dans les cieux à la rescousse de la belle Panphilie au I.X; dans I'Au-delà mythologique quand il est descendu aux Enfers des Anciens après son feint suicide au I.XII. L'extra-vagant est structurellement en tangence avec la logique de la fiction dont il relève; cet être de papier au carré est incompatible avec l'ordonnance dynamique du récit.

L'extravagant, issu des contresens narratifs qu'il a commis, grippe la narration et la fait extravaguer à son tour. On a souvent reproché au roman sa longueur, qui lui conférerait illisibilité et inintérêt; tout au moins cette ampleur, incontestable, a-t-elle valeur fonctionnelle, celle de la démultiplication, de l'emballement des récits autour de l'extravagant. L'action représentée - un jeune homme extraordinairement amoureux finit par épouser celle qu'il aime, une fois guéri de la pathologie mélancolique qui l'affecte - s'enfle des récits inventés par Lysis, nous les avons évoqués. Elle s'enfle aussi de ceux que rapportent les

\footnotetext{
11 “il dit à Anselme, Voyez vous que les Peintres de Paris ont déja ouy parler de moy? Tenez ils m'ont peint avec mon habit de Berger et ma houlette. Anselme regarda et vid un Berger en peinture dedans cette boutique, qui par hazard avoit bien de l'air de Lysis" (III, 353-354).

12 III, 433-434, 463; IV, 531-532; IV, 563; X, 370-374; XI, 557, XII, 652-653... Sur cette construction verbale du personnage, nous nous permettons renvoyer à Spica, à paraître.
} 
personnages qui l'entourent (I, II, III, V, VII-VIII, X, XI, XII): la plupart résultent des mises en scène successives imaginées par ces mêmes personnages en vue de donner de nouveaux développements à l'extravagance de leur patient - et de trouver de nouveaux sujets d'amusement. Sur cette hypertrophie narrative se greffent les leçons sur la fiction, assumées par les personnages intradiégétiques (III, VIII, XIII, XIV) ou par les Remarques, dans lesquelles viennent en outre s'interpoler d'autres narrations en guise de nouvelles preuves à charge ou à décharge de la fiction.... Le récit proliférant pour lui-même, progressivement décentré de son propos - amener deux amants initialement séparés à leur mariage, conformément à la structure du roman identifiée par les contemporains de Sorel - tourneraitil donc à l'incohérence, à l'enlisement, à l'addition sans limites de péripéties, puisqu'il s'agit moins de préparer par de longues épreuves l'initiation à la sagesse amoureuse, toute néoplatonicienne, d'un couple idéal que de surenchérir en tours et détours de la fiction, n'était la décision brutale au livre XIV de mettre un terme à cette extravagance topique autant que diégétique?

On le sait: la valeur métadiégétique de la sottise et de la folie, en particulier de la "folie par identification romanesque" (Foucault: 1976, p. 47-48) dont l'extravagance du berger offre une des variations les plus accomplies, joue un rôle essentiel dans la fondation du roman moderne, affichant depuis le Quichotte les pouvoirs de la fiction ${ }^{13}$. L'extravagance de Lysis, mais aussi celle de la diégèse qui l'expose en est une excellente démonstration. À travers elle, Sorel pose les bases de la théorie romanesque telle qu'il entend la rénover: celle d'une mimesis dont la plus ou moins grande tangence au réel ne sera pas illusionniste mais instructive.

\section{Des vertus centripètes d'une fonction centrifuge}

C'est bien cette réévaluation morale qui est à l'œuvre dans l'expansion narrative à l'instant évoquée. L'extravagance procède comme un "pré-texte", dont le roman qui la décrit, comme son palimpseste (Genette, 1982), constitue le texte digne en définitive d'être reçu par le lecteur. Les cent mille milliards de romans que l'extravagance fait proliférer identifient des relais de lecture: l'extravagance est une anamorphose que la diégèse qui l'assume redresse à mesure qu'elle l'énonce, car sa nature narrative est de déterminer un point de vue plus qu'un objet constitué en soi.

\footnotetext{
13 La bibliographie est conséquente à ce sujet; pour le roman d'Ancien Régime et pour Sorel, voir entre autres, Franchetti, 1976; Bakhtine, 1978: 214-233; Genette, 1982: 168; Niderst, 1995; Sermain, 1999 et 2002; Fournier, 2006: 124-129.
} 
Ce qui fonde l'extravagance de Lysis, et avant lui celle des fables et des romans condamnés par Sorel, hellénistiques sur le modèle des Éthiopiques et pastoraux comme L'Astrée, c'est le rapport falsifié au vraisemblable ${ }^{14}$ et, partant, aux procédures interprétatives qu'ils convoquent. D'une part, ces textes reposent sur une faute gravissime aux yeux du romancier polygraphe: ils font passer le vraisemblable interne à leur narration, celui du système topique adopté en son sein qui en assure la cohérence narrative, pour le vraisemblable externe référentiel, celui qui suscite l'identification du lecteur ${ }^{15}$. Lysis incarne l'imago agens de cette superposition fallacieuse, lui qui croit que les conventions vestimentaires, amoureuses et sociopolitiques qui régissent L'Astrée façonnent le quotidien référentiel où il évolue.

D'autre part, et c'est la raison pour laquelle Sorel stigmatise avec tant de violence au début de son roman "les absurditez de la Poësie" avec celle des romans, ce corpus trouve sa légitimité dans la lecture allégorique que l'on peut en faire, dans la mesure où l'on considère communément les fictions narratives en prose comme les descendantes de la Fable antique, sur le modèle des métamorphoses ovidiennes ${ }^{16}$; l'interprétation à plus haut sens, d'ordre moral, en justifiera toujours l'apparente absurdité ${ }^{17}$. Or pour Sorel, une telle conception est intenable: non seulement le récit de métamorphoses et son allégorèse n'ont aucun sens, ni moral ni esthétique, comme le démontrent les interventions de Clarimond, le porte-parole intradiégétique de l'auteur aux moments-clefs du récit18: on peut leur faire dire ce que l'on veut et leur contraire; mais Le Berger extravagant tout entier, en les poussant à leurs dernières extrémités pour en montrer l'incohérence, offre la réinterprétation follement continuée de ces récits "impertinents" - l'adjectif revient constamment sous la plume de Sorel -, ou en d'autres termes dépourvus de tout contenu interprétable. Or des textes insignifiants, au sens littéral de l'adjectif, ne peuvent prétendre offrir au lecteur le moindre cadre de créance: il faut - et telle est l'entreprise de Sorel, lorsqu'il prend l'extravagance de son personnage comme levier d'Archimède - remettre en perspective les lignes de fuite de la fiction bien comprise.

\footnotetext{
14 Sur les discussions autour de la notion de vraisemblable romanesque au XVII ${ }^{\mathrm{e}}$ siècle et de ses variations, voir Esmein, 2008.

15 Nous ne reprenons pas ici la démonstration qui figure dans Spica, 2008.

16 C'est encore ce que propose P.-D. Huet dans le Traité sur l'origine des romans en tête de Zayde de Mme de Lafayette (1670). Nous nous permettons de renvoyer à Spica, 2010.

17 Sur la mise en place de cette légitimation au $X \mathrm{VI}{ }^{\mathrm{e}}$ siècle en France, liée à l'invention de la catégorie générique du roman à travers celle de l'“histoire fabuleuse", voir l'introduction de M.-M. Fontaine à son édition de Aneau, 1996, t. 1, p. XL-LXVIII; Mounier, 2007 et 2007b.

18 En inventant une parodie mythologique, "Le banquet des dieux" (III, 359-426); en argumentant contre Lysis lorsqu'il croit s'être métamorphosé en saule (V, passim) ou lorsqu'il veut métamorphoser Carmelin (VII, 9821012); dans le long procès des romans au I. XIII; ces positions sont fermement soutenues au long des remarques afférentes.
} 
II n'est dès lors pas indifférent que l'extravagance de Lysis soit précisément une forme pathologique de la mélancolie érotique. Comme Amyot l'a établi à sa naissance au $\mathrm{XVI}^{\mathrm{e}}$ siècle et comme l'a résumé Huet au cours du XVII siècle,

Ce que l'on appelle proprement des romans sont des histoires feintes d'aventures amoureuses, écrites en prose avec art, pour le plaisir et l'instruction des lecteurs. [...] La fin principale des romans [...] est l'instruction des lecteurs, à qui il faut toûjours faire voir la vertu couronnée; et le vice chastié. ${ }^{19}$.

La diégèse amoureuse telle que la proposent les romanciers ou les mythographes, qui jusqu'à présent ont construit un modèle romanesque fondé sur la collusion entre immersion dangereuse et illégitimité herméneutique, conduit à récuser le roman qui ne peut plus reposer sur une telle matrice; l'extravagance du berger, miroir de celles auxquelles il adhère, construit le contre-modèle exact à partir duquel inventer un autre régime de la fiction, acceptable et légitimable aux yeux de Sorel. Puisque l'injonction que lançait le poète latin Horace dans l'Épître aux Pisons, miscere utile dulci, encore fondatrice de l'exercice littéraire au $\mathrm{XVII}{ }^{e}$ siècle, prend dans le cas du roman la figure d'un intenable paradoxe - le récit amoureux ne peut plus instruire, et il abuse en plaisant - il convient d'assumer jusqu'au bout ce paradoxe: instruire sur la fiction en plaisant par la distance vis-à-vis de la fiction, c'est-à-dire assumer radicalement la métalittérarité à la base du roman à travers l'écriture comique conçue, grâce à la mise en scène fictionnelle de l'extravagance, comme la rectification des errances de l'écriture hellénistique et pastorale.

Lysis s'apprête à (feindre de) se suicider, dans un redoublement (calculé) d'extravagance 20 , au terme d'un raisonnement parfaitement emblématique de la conception du roman que Sorel défend. Mourir d'amour, ce n'est pas se conformer à une éthique courtoise qui transcenderait le monde réel par sa sublimation au sein de la mimesis fictionnelle 21 mais c'est contrevenir à toute raison. Mourir d'amour par amour pour la fiction, c'est mourir doublement pour rien. Lysis ne tardera pas à feindre le retour à la vie dans le même épisode, et ce réveil à la fin du I.XII, préludant à la fois la longue controverse contre les romans au I.XIII et le dessillement du Berger au I.XIV, assure par anticipation une "bonne" fin à tous les sens du terme: l'issue du roman avec le mariage de Lysis.

\footnotetext{
19 La publication (1670) est postérieure à la rédaction. Nos citations dans l'éd. Paris, Barbin, 1670, ici p. 4-5; voir aussi Esmein, éd., 2004, p. 359-535.

20 "Il faut obeyr un moment à ma maistresse, pour ne luy plus obeyr apres. Je veux executer son commandement sans commandement." (XII, 688)

21 Puisque l'opération mimétique, selon Aristote, conduit à achever dans l'ordre du nécessaire et du vraisemblable ce qui n'est qu'imparfait dans le monde sublunaire.
} 
L'extravagant romanesque, parce qu'il divague et fait divaguer le récit, se fait le repoussoir de la fiction bien entendue et attire l'attention sur sa mécanique même; il offre au lecteur un point de vue ultime et négatif, interdisant l'identification, à partir duquel prêter moins attention au contenu des aventures - dont l'interprétation ne s'impose plus - qu'à la forme poiétique qu'elles prennent. L'extravagance fictionnelle relève ainsi du calcul herméneutique sur lequel fait fonds le romancier averti, qui doit donc en garder toute la maîtrise:

Dans le Pelerin de Lope de Vega il y a une histoire d'un Chevalier Espagnol appellé Fabio qui est berger dans l'Espagne mesme, et qui garde en effect les moutons d'une mestairie, estant porté à cela par le changement de sa maistresse. II raconte ses amours d'un stile le plus grotesque qui fut jamais, et nous fait connoistre qu'encore que Lope ait parlé de luy serieusement, il fait sans y penser un berger encore plus extravagant que le nostre: car il est plus estrange de voir qu'un gentilhomme de qualité s'est fait Berger, que non pas le fils d'un marchand, qui n'a quasi rien veu que ses livres; et puis ce qui est de plus vilain, c'est que Fabio est un valet mercenaire et est plustost Pastre que berger (comme les remarques de Lysis nous font connoistre) au lieu que nostre Lysis est un de ces Bergers illustres qui donnent des sujets aux faiseurs de Romans et paroissent sur les theatres. (R.XII, 748).

L'extravagance bien entendue relève d'un arrangement dans le système des probabilités qui constituent le monde possible romanesque, de manière à exhiber ses paramètres de composition et à attirer l'attention du lecteur sur leur caractère artificiel. Grâce à l'intervention de l'extravagant et à l'extravagance qu'il apporte au déroulement narratif que le lecteur pouvait programmer en fonction de son habitude des romans, le roman apparaît comme un artefact. Partant, son naturel, son vraisemblable en tant qu'artefact est bien de souligner sans ambiguïté sa nature artificielle:

Ce qui est de remarquable en toutes les histoires qui se racontent icy ${ }^{22}$, est que leur beauté ne les empesche pas d'avoir quelque extravagance pour se mocquer de Lysis. L'histoire de Genevre et celle d'Alican, et les amours d'Anselme et d'Angelique, et d'Hircan et d'Amarylle sont aussi pour monstrer la difference qu'il y a entre les amours des personnes du monde, et celles des personnages des Romans. (R.XIV, 1087)

Dans un roman très soigneusement construit, la prolifération précédemment relevée ressortit en réalité à l'amplification ordonnée, intégrée au "pacte critique" (Rosellini, 2004:

22 Sorel évoque ici la part comique de son roman, portée par Anselme et ses compagnons lorsqu'ils ne se moquent pas de Lysis. 
388) inhérent aux romans français hérités du Quichotte, grâce aux commentaires de Clarimond ou aux Remarques qui viennent déjouer les effets d'immersion dans le récit. Décliner une à une les facettes de l'extravagance revient ainsi à éprouver tous les points aveugles d'un modèle inadéquat pour en démontrer intégralement l'inanité. Cette déclinaison est à la source de l'agrément rencontré à la lecture du roman, un agrément à la fois plaisant et instructif.

\section{Que l'extravagance est le plus court chemin vers la littérature}

Le plus extravagant n'est donc pas celui que l'on croit. Sorel prend un malin plaisir à disqualifier les textes mythologiques qui ont bénéficié de l'attention allégorique érudite la plus révérende 23 , les ouvrages historiques sur lesquels tout un pan de la translatio studii et imperii vers la France s'est établie ${ }^{24}$ ou les romans qui adoptent une topique amoureuse "sérieuse"25. Ils témoignent en réalité d'une extravagance consommée et Lysis est finalement un personnage raisonnable, puisqu'il n'a fait qu'épouser la logique de ces récits admirables:

L'obscurité du lieu, et l'estonnement de Lysis servent beaucoup à luy faire prendre Leonor pour Charite, et si en d'autres lieux il a pris encore des personnes pour des autres, il ne sçauroit trouver cela extraordinaire, et ne sçauroit croire qu'il doive estre estimé extravagant pour ce sujet: car toutes les avantures des Romans ne sont composées que de semblables choses. Nos Autheurs n'ont point d'autre invention, que de feindre que leurs personnages se trompent tousjours, et se prennent les uns pour les autres. (R.XI, 605)

\footnotetext{
23 "Turnus voulant brusler les navires d'Enee, Cybele les metamorphosa en des Nymphes Nayades pour empescher son dessein. Voila des navires bien heureuses, encore que cela ne servist de rien de les conserver de la sorte, puisque tousjours Enee en estoit privé. Les Poëtes ne feroient pas tant d'honneur à des femmes qui auroient vescu vertueusement. L'on trouvera par tout de semblables exemples qui monstrent l'impertinence des metamorphoses d'Ovide et des autres Autheurs; et quant à celles qui sont ordonnées pour punition, quelle absurdité n'ont elles point encore? Toutes les meilleures que l'on se puisse imaginer sont celles qui se font d'un homme en quelque beste dont il a eu le naturel, et neantmoins cela n'est pas beaucoup à propos, car si un homme a l'ame adonnée aux salletez, n'est-ce pas l'obliger plustost que de le punir, que de le changer en un pourceau." (R.XIV, 1078)

24 "Le plus impertinent de tous les historiens qui ont parlé de la venuë de Francus en Gaule, est Jehan Le Maire de Belges, qui pour prouver que nostre genealogie vient de Troye, raporte tout au long ce qui est dans Homere, dans Ovide, et dans d'autres Poëtes, et met apres nostre histoire. II faloit avoir le jugement bien troublé pour vouloir trouver la verité dans les fables; encore ne la trouve-t'il point sans forger d'autres fables luy mesme: car Homere ne dit point qu'Hector eust un autre fils qu'Astianax lequel fut tué par Pyrrhus, à ce que disent plusieurs Autheurs." (R.XIII, 936-937)

25 "Hircan represente naïvement l'humeur des bergers de nos livres qui sont tous des amoureux transis dont il se mocque. Fontenay fait semblant de s'esvanoüyr, en quoy il reforme les Romans où vous voyez que les Amans se pasment tousjours devant leurs maistresses. Cettuy-cy ne croit pas que cela se fasse facilement et que les autres s'esvanoüyssent tout à bon. II pense qu'il y doit avoir de la feinte." (R.XII, 752-753)
} 
À sauts, à gambades et à boutades, l'extravagance s'éprouve de manière ludique et plaisante, suscitant une série de connivences. Elle constitue le lien qui unit tous les personnages autour de Lysis. Ils donnent de concert son assise au comportement extravagant de Lysis en lui fournissant toujours une occasion d'imiter absurdement un nouveau topos romanesque, pour en tirer le plus grand plaisir. C'est même la raison d'être du groupe - outre celle de la longueur de la narration ${ }^{26}$. L'interrompre, c'est briser l'harmonie railleuse et c'est bien ce que refusent les compagnons du berger:

Ha messieurs, poursuivit [Adrian] en se tournant vers les assistans, vous avez tort de prendre icy vostre plaisir de ce pauvre garçon. II est vray que vostre cousin nous donne du plaisir, dit Anselme, mais c'est pource qu'il a plus d'esprit que nous pour inventer tous les jours de nouveaux jeux. (XI, 563-564)

Pour autant, ce n'est pas cette connivence-là qui est proposée en modèle par Sorel; Clarimond convainc le groupe de dessiller Lysis, entre les I.XII et XIV. En effet, faire de l'extravagant un bouffon ${ }^{27}$ ne suffit pas à détourner des romans condamnés pour leur extravagance structurelle un lecteur qui ne serait que spectateur; après tout, le risque de l'identification du lecteur au souffre-douleur, si extravagant soit-il, n'est pas nul, et c'est bien cette caractéristique que soulève Clarimond pour décider ses compagnons ${ }^{28}$. S'il y a connivence plaisante, "agreable", elle ne peut passer qu'au niveau extradiégétique, dans le plaisir conscient qu'il y a à poursuivre un récit dont la lecture est "déniaisante"29. Philiris, le défenseur des romans lors de la discussion pro et contra du I.XIII, rétorque en ces termes aux objections d'extravagance que Clarimond opposait aux Bergeries de Julliette de Nicolas de Montreux, le grand roman pastoral de la fin du XVI siècle en France:

Que s[i Montreux] fait que les filles prient les hommes d'amour, c'est qu'il veut representer que l'on vivoit au lieu où elles estoient comme en l'âge d'or, pendant lequel les loix de l'honneur n'estoient pas inventées. Que si en racontant des histoires elles citent des Autheurs prophanes et sacrez, et parlent mesme des choses arrivées de nostre temps, c'est que tout cela n'estant que feinte, et chacun sçachant bien que

26 "Pour que cesse le récit, il faut que le berger se taise et qu'avec lui disparaissent tous les possibles narratifs qu'il avait disséminés au cours de son périple; à l'inverse, pour les comparses, il faut empêcher celui-ci de se taire afin de ne point perdre les promesses de jeu." (Chouinard, 2000: 102-103.)

27 Sur la transformation de l'extravagant en bouffon dans le roman de Sorel, voir Chouinard, 2000 et Rosellini, 2004.

28 XII, 713-714, XIII, 737; on en rapprochera toutes les notations de la souffrance d'Adrian, lui aussi victime des compagnons de Lysis, lorsqu'il vient rechercher son pupille au I.XII.

29 "Déniaiser" est le verbe privilégié par les libertins philosophes, au début du XVII siècle, pour évoquer le savoir qu'ils apportent au risque de briser l'orthodoxie théologique et scientifique. Nous reprenons à dessein ce verbe pour qualifier le dessillement en matière de fiction que propose le compagnon de route de ces mêmes libertins dans les années 1620 . 
c'est l'Autheur qui parle par tout, il a pris la licence de faire les choses autant à la mode de ce siecle que des siecles passez, afin de donner plus de plaisir aux lecteurs. (XIII, 875)

L'extravagance n'est gênante que pour qui refuse de voir le jeu de la fiction et donc le plaisir qu'il y a à en tirer, jeu qui n'est pas, nous l'avons vu, de prendre au pied de la lettre cette fiction ni de l'interpréter, mais de la mettre à distance. Vouloir interpréter la fiction revient donc à se tromper d'objet à interpréter et c'est bien là que réside l'extravagance la plus dangereuse, voilée sous le masque d'une prétendue raison.

Que si quelqu'un me remonstre que j'espluche la Poësie de trop pres, et que j'ay tort de la vouloir rendre ridicule, pource que ses fables sont autant de mysteres, et qu'il n'y a rien qui n'ait un sens caché, je respondray que l'on treuve tout ce que l'on veut par Allegorie dans quelque narration que ce soit, et qu'à un mesme suject un esprit inventif peut donner dix mille explications; mais que ce n'est pas à dire que le Poëte ait songé à cacher de si belles veritez dessous ses fables; Aussi quand j'avoürois que les Poëtes auroient songé à couvrir quelques secrets, je nierois qu'il y en ait aucun qui y ait bien reüssy. Leurs fictions sont trop entremeslées pour y trouver quelque chose de certain. (XIII, 814-815)

Elle se révèle antinomique du plaisir qui fonde le pacte de lecture bien entendu, celui de la reconnaissance mutuelle d'une ingéniosité formelle chez l'auteur et le lecteur. Au contraire, une extravagance calculée, celle des récits enchâssés proposés par Sorel en contrepoint des parodies romanesques (les fables du dieu Morin et de la rivière de Marne, de la fontaine Synope, de la fontaine Lucide, du cyprès et des deux hamadryades au I.V, les histoires de Fontenay, de Philiris, de Polidor, de Meliante et de Carmelin aux I.VII et VIII, l'histoire de Clarice et celle d'Alicante au I.XI), facilite pleinement l'identification des procédures fictionnelles: "Je pense que toute la vray-semblance qui s'y peut observer s'y rencontre" (R.XIII, 913).

Ainsi, mettre la fiction hors du jeu et du plaisir, c'est la mettre hors-jeu absolument, c'est la rendre proprement extravagante. Sorel, par ce geste, s'inscrit dans un mouvement profond du XVII ${ }^{e}$ siècle lecteur mis au jour par Philippe Caron (1992), qui consiste à séparer la littérature, de plaisir et autoréférentielle, du reste des Belles et Bonnes Lettres, celles qui nécessitent une érudition et un savoir-faire interprétatif préalables. Sorel, avec Le Berger extravagant, participe de plain-pied à la naissance de la littérature en même temps qu'il 
participe à celle de l'écrivain ${ }^{30}$. S'il y a allégorie dans le roman, elle est de nature stylistique, formelle, et non plus sémantique:

L'on fait beaucoup d'estime des fables des Poëtes, pource que l'on s'imagine qu'elles ont de rares explications: mais si le Roman de Lysis a des avantures qui surpassent celles des autres, il n'est pas non plus destitué de cet avantage de pouvoir employer ceux qui cherchent des mythologies. J'en ay déja fait sur le Banquet des Dieux et autrepart, et principalement sur les deux comedies que l'on jouë avec nostre Berger, lesquelles sont si remarquables que l'on n'en a jamais veu de si plaisantes, soit pour le langage, soit pour les actions: mais j'excuse les femmes et ceux qui faute d'avoir estudié ne prennent pas tant de plaisir à cela qu'ils feroient à quelque conte de village et ne sçavent pas ce que c'est que des diverses figures de Rhetorique. (R.XIV, 10881089).

Ainsi, autant il est extravagant d'aller chercher à toute force un sens caché dans une fiction, autant il serait absurde de bouder son plaisir esthétique. L'allégorie, dont on sait combien le $\mathrm{XVII}$ siècle engage la disqualification stylistique, n'est même plus rédimable comme "figure de rhétorique". On appréciera donc les romans pour la subtilité de leurs ornements langagiers. Sorel défend tout au long des Remarques du Berger extravagant, comme il l'a fait pour Francion, l'adéquation entre fiction et style moyen ${ }^{31}$, légitimant par là l'écriture comique; les autres romanciers et grands théoriciens du roman après lui que sont Georges et Madeleine de Scudéry, de leur côté, ne concevront pas autrement ni le roman de longue haleine, ni les nouvelles. Car il est vrai que ce style est celui de la conversation et des petits genres galants, dont Sorel a été aussi un grand praticien: ceux-là même qui dessinent, au $\mathrm{XVII}{ }^{e}$ siècle en France, les nouveaux rivages de la littérature, ceux où le plaisir du texte rejoint le contentement esthétique du lecteur, et c'est bien là que réside l'éthique d'une telle écriture.

Le roman délivré des soupçons qui pèsent sur lui, serait-il finalement... de l'allégorie extravagante? En tout état de cause, cette configuration seule rend entièrement compte du le plaisir propre et moral de la lecture des fictions, et tel est, en définitive, l'accord de l'utile dulci en roman selon Sorel:

30 Sur les stratégies auctoriales de Sorel qui le placent dans le camp des écrivains, voir Viala, 1980; Roux, 2011.

31 Sorel emploie constamment et élogieusement à propos des effets qu'il recommande le qualificatif "naïf" au sens que le $\mathrm{XVII}^{e}$ siècle donne à cet adjectif, celui d'un naturel propre au genre capable d'épouser toutes les situations narratives. Un exemple parmi de nombreux autres (nous soulignons): Quant à l'histoire de Philiris n'at'elle pas plus de naïvetez et de belles pensées que les histoires amoureuses que l'on fait pour estre vraysemblables (R.XIV, 1080). 
Apres avoir tout meurement examiné, nous ordonnons que puisque tous ces ouvrages fabuleux ne sont faits que pour donner du plaisir, et que le dessein des Escrivains reüssit assez bien quand ils peuvent recréer les lecteurs. (XIII, 891)

En exploitant méthodiquement les ressources thématiques, narratives et poétiques que lui fournit la figure de l'extravagant en roman, l'auteur du Berger extravagant remplit les trois volets du contrat proposé à son lecteur. La "sortie de route" hors des topoï romanesques en vogue au début du XVII siècle, loin de ne constituer qu'un catalogue de fantaisies plus ou moins amusantes, érige l'extravagant en point de mire grâce auquel elle démontre les apories d'une fiction entièrement conçue en fonction d'une immersion bien trop complaisante du lecteur. Elle oblige ce dernier à interroger les critères de validation d'un récit fictionnel - vraisemblance et créance - pour mieux appréhender les ambiguïtés que comporte son système de référence. En validant, enfin, le sérieux générique du roman comique, la structure extravagante de l'anti-roman pose les cadres d'une théorisation pragmatique du roman qui n'a cessé de séduire les anti-lecteurs. 


\section{Bibliographie}

ALET, Martine, 2002. "Étude psycho-physiologique du Berger extravagant de Charles Sorel: la mélancolie de Louys". In: Papers For Seventeenth-Century Llittrature, 29, n 56, pp. 153-175.

ANEAU, Barthélemy, 1996. Alector ou le coq, histoire fabuleuse [1560], éd. Marie-Madeleine Fontaine. Genève: Droz.

BAKHTINE, Mikhaïl, 1978. Esthétique et théorie du roman, trad. fr. Paris, Gallimard (collection "Tel").

BARDON, Maurice, 1931. Don Quichotte en France au XVII et au XVIII siècle, 1605-1815. Paris: Imprimerie des presses modernes.

BLANCKAERT, Amélie, 2004. "De la folie à la sottise: réécriture du personnage de Don Quichotte dans le roman français de la première moitié du XVII ${ }^{e}$ siècle". In: Nicole Jacques-Lefèvre et AnnePascale Pouey-Mounou (éds). Sottise et ineptie, de la Renaissance aux Lumières: discours du savoir et représentations romanesques. Nanterre: Littérales, Centre des Sciences de la Littérature française de Paris X -Nanterre, pp. 367-385.

CARON, Philippe, 1992. Des belles lettres à la littérature: une archéologie des signes du savoir profane en langue française, 1680-1760. Louvain/ Paris: Peeters.

CHOUINARD, Daniel, 2000. 'La métamorphose du lecteur en bouffon: 'jouer' et 'jouir' dans Le Berger extravagant". In: Daniel Riou (dir.). Lectures du Francion de Charles Sorel. Rennes: PUR, pp. 99106.

ESMEIN, Camille, éd., 2004. Poétiques du roman. Scudéry, Huet, Du Plaisir et autres textes théoriques et critiques $d u X V I I^{e}$ siècle sur le genre romanesque. Paris: $\mathrm{H}$. Champion.

ESMEIN, Camille, 2008. L'Essor du roman. Discours théorique et constitution d'un genre littéraire au XVII siècle. Paris: H. Champion.

FOUCAULt, Michel, 1976. Histoire de la folie à l'âge classique. Paris: Gallimard (collection "Tel").

FOURNIER, Michel, 2006. Généalogie du roman. Émergence d'une formation culturelle au XVII ${ }^{e}$ siècle en France. Sainte-Foy, Presses de l'Université Laval.

FRANCHETTI, Anna Lia, 1976. "Il Berger extravagant o l'inganno della rappresentazione". Paragone, $\mathrm{n}^{\circ} 318$, pp. 45-68.

GenetTe, Gérard, 1982. Palimpsestes. La littérature au second degré, Paris: Seuil.

LAVOCAT, Françoise, 1998. Arcadies malheureuses. Aux origines du roman moderne. Paris: H. Champion.

MOUNIER, Pascale, 2007, "Le récit et ses formes: les tâtonnements de la terminologie narrative du $\mathrm{XVI} \mathrm{I}^{\mathrm{e}}$ siècle". In: Pascal Selosse et Mylène Paquant (dirs). "Les dénominations du savoir en français préclassique", Actes du colloque international de Lyon des 24-25 juin 2005, $n^{\circ}$ spécial de la revue Le Français préclassique, $\mathrm{n}^{\circ} \mathrm{X}, \mathrm{pp} .249-267$.

MOUNIER, Pascale, 2007b. Le roman humaniste, un genre novateur français, 1532-1564. Paris: H. Champion.

NIDERST, Alain, 1995. "Le danger des romans dans les romans du XVII ${ }^{e}$ siècle". In: Jan Herman et Paul Pelcmans (éds). L'épreuve du lecteur, livres et lectures dans le roman d'ancien régime. Leuven: Peeters, pp. 52-58.

ROSELLINI, Michèle, 2004. "Le sot lecteur et l'auteur facétieux. Élaboration d'une fiction critique dans les premières adaptations françaises du Don Quichotte". In: Nicole Jacques-Lefèvre et AnnePascale Pouey-Mounou (éds). Sottise et ineptie, de la Renaissance aux Lumières: discours du savoir et représentations romanesques. Nanterre: Littérales, Centre des Sciences de la Littérature française de Paris X -Nanterre, pp. 387-407.

Roux, Olivier, 2011. La "fonction d'écrivain" dans l'œuvre de Charles Sorel, thèse de doctorat nouveau régime, dir. D. Bertrand. Clermont-Ferrand II (à paraître remaniée. Paris: H. Champion).

SermaIn, Jean-Paul, 1999. Le Singe de don Quichotte: Marivaux, Cervantes et le roman post-critique. Oxford: Voltaire Foundation. 
SERMAIN, Jean-Paul, 2002. Métafictions (1670-1730), la réflexivité dans la littérature d'imagination. Paris: H. Champion.

SERROY, Jean, 1981. Roman et réalité, les histoires comiques au XVII siècle. Paris: Minard.

SPICA, Anne-Elisabeth, 2008. "Charles Sorel lecteur de L'Astrée”. In: Delphine Denis (éd). Lire L'Astrée. Paris: PUPS, 2008, pp. 287-298.

SPICA, Anne-Elisabeth, 2010, "Charles Sorel et la métamorphose: définir le roman moderne". In: Poétique, $\mathrm{n}^{\circ} 164$, pp. 433-446.

SPICA, Anne-Elisabeth, à paraître. "L'extra-vagant et le roman: l'exemple du Berger extravagant de Charles Sorel". In: Bertrand Gervais, Marie Scarpa (orgs). Idiots, figures et personnages liminaires (colloque de Montréal, UQAM, 28-29 octobre 2010). À paraître aux Presses universitaires de Nancy (collection "Recherches en ethnocritique").

VIALA, Alain, 1980. Naissance de l'écrivain. Paris: Minuit.

ZeRARI-PENIN, Maria, 2007. "Don Quichotte Berger: de Cervantès à Charles Sorel". In: Estrella RuizGálvez Priego et Gilles Groult (dirs). Don Quijote de la Mancha dans la Manche, Études à l'intention des Archives départementales de la Manche, faites à l'occasion du quatrième centenaire de la parution de la Première partie de Don Quichotte sur les presses de Juan de la Cuesta à Madrid, en 1605. Paris: L'Harmattan, pp. 115-133. 